\title{
Action of Pentoxifylline on Experimental Cutaneous Leishmaniasis Due to Leishmania (Leishmania) amazonensis
}

\author{
Thiago de Sá Oliveira, Mário Capp Neto, Bernardo José Alves Martins, Helbert \\ Abe Rodrigues, Rosa Maria Parreiras Antonino, Albino Verçosa Magalhães ${ }^{+}$
}

\author{
Departamento de Patologia, Universidade de Brasília, 70910-900 Brasília, DF, Brasil
}

In the animal model of leishmaniasis caused by Leishmania (Leishmania) amazonensis there is a complex mechanism of the host-parasite interaction. The present study was performed to interfere with the inflammatory reaction to the parasites, through immune modulation. Female C5BL/6 isogenic mice were used, some of which were inoculated on the right ear and others on the right footpad with $3.10^{6}$ stationary phase promastigotes of the MHOM/BR/PH8 strain of L. (L.) amazonensis, and were allocated in three groups: the first received pentoxifylline $8 \mathrm{mg} / \mathrm{kg}$ every $12 \mathrm{~h}$, since the first day; the second one received the same dose since the 40th day of infection and a control group that did not receive any treatment. All the ears excised were analyzed to determine the variation in weight between both ears and for histopathological analyses. A quantification of the parasites was done using the limiting dilution assay. A significant reduction of the number of parasites, was observed among the animals treated which had an accordingly significant reduction on the weight of the ears. Pentoxifylline reduced the macrophages propensity to vacuolation and induced a more effective destruction of the parasites by these cells. Moreover, the group that began the treatment later did not show the same effectiveness.

Key words: pentoxifylline - Leishmania (Leishmania) amazonensis - tumour necrosis factor-alpha

On the experimental infections with protozoal of the genus Leishmania, the host's resistance or susceptibility to the parasite is determined by the response offered by the T lymphocytes of the Th 1 subset or the Th 2 subset (Mukherjee et al. 1990, Solbach \& Laskay 1996). In fact, it has been shown that cellular based immunity is the main mechanism of defense against these protozoa (Liew et al. 1990a). In general, intracellular parasitism is associated with the induction of the Th 1 subset response [including the cytokines interleukin-1 (IL-1), IL-2, IL-12, interferon-gamma (IFN- $\gamma$ ), tumour necrosis factoralpha (TNF- $\alpha$ )] though it may also occur due to the Th 2 subset response [including the cytokines IL6, IL- 9, IL- 10, transforming growth factor-beta (TGF- $\beta$ ), IL- 13] (Sullivan et al. 1988, Liew 1990b, Cerami 1992, Barral-Netto \& Barral 1994, Borish \& Rosenwasser 1996, Solbach \& Laskay 1996, Van Furth et al. 1997).

\footnotetext{
This work was supported by CNPq, FAPDF and UnB. ${ }^{+}$Corresponding author Fax: +55-61-273.0105. E-mail: albino@unb.br

Received 19 May 1999

Accepted 9 February 2000
}

In order to perform the experiment, we used pentoxifylline xanthine (Trental ${ }^{\circledR}$ ) which is able to function in a variety of cells, including macrophages, NK cells and neutrophils and causes distinct effects on each type. Among the main cellular actions determined by this drug are modulations in the production of cytokines. In fact, it inhibits, in a dose-dependent manner, the synthesis of TNF- $\alpha$ by macrophages (Reed \& Degowin 1992), the synthesis of IL-2, IL-12 and INF- $\gamma$, and influences the production of other cytokines, such as IL-4, IL-6 and IL-10 (Strieter et al. 1988, Neuner et al. 1994). These observations indicate that pentoxifylline acts by stimulating changes in the cellular response from the Th 1 subset to the Th 2 subset. The extrinsic modulation of the immune response induced by this drug may help in the search for a better understanding of the meaning of the participation of the cells in the pathogenesis of the disease and of the factors released by them, mainly the cytokines.

Pentoxifylline xanthine has an important action on the polymorphonuclear leukocytes, mainly through neutralization of the stimulating effects of IL-1 (Weinberg et al. 1992) and TNF- $\alpha$ upon the cells (Strieter et al. 1988, Varani et al. 1988, Hand et al. 1989, Schade 1990, Neuner et al. 1994). This drug has shown to have a potent inhibitory action on the production of IL-12. The suppressive effects of this drug upon the production of IL-12 may be in- 
hibited by previously existing IFN- $\gamma$, which reduces its utilization in chronic diseases where IFN- $\gamma$ is being produced (Moller et al. 1997).

TNF- $\alpha$ synthesis in peritoneal macrophages has been found to be blocked by pentoxifylline, through its inhibitory action upon mRNA, through the inhibition of phosphodiesterase and the increase in intra-cellular cAMP (Schade 1990, Doherty et al. 1991, Schandené et al. 1992, Loftis et al. 1997). Pentoxifylline, besides the inhibition of the synthesis of TNF- $\alpha$, seems to promote the deviation of the cellular secretion towards the production of cytokines of the Th 2 subset, such as IL- 4 and IL10 , inhibiting, on the other hand, the cytokines of the Th 1 subset, such as IFN- $\gamma$ and IL-2 (Moller et al. 1997).

In the present research, it was our intention to modify in the inflammatory response to the parasites through the development of an experimental model of cutaneous leishmaniasis by L. (L.) amazonensis $[L(L) a]$, in isogenic mice, with the goal of improving our knowledge of the pathogenetic mechanisms of the lesion.

\section{MATERIALS AND METHODS}

Parasites and animals used - In order to infect the animals, we used the MHOM/BR/PH8 strain of $L(L) a$, isolated from an human case of tegumentary leishmaniasis. The parasites were maintained in mice hind footpad, assessed by puncture and replicated into NNN medium for 10 days, after that grown in the RPMI 1640 medium (Sigma Chemical Company, St. Louis, MO, USA). Sixty four female isogenic mice of the strain C57BL/6 originating from the living animal reserve of the Pathology Laboratory of the University of Brasília, were inoculated with $3.10^{6}$ promastigote forms from the stationary phase.

Treatment with pentoxifylline - Forty animals were treated with pentoxifylline (Treated Group $P t x$ ), using $8 \mathrm{mg} / \mathrm{kg} / \mathrm{mass}$, every $12 \mathrm{~h}$, intraperitoneally, divided in five subgroups, each with eight animals, six of which were inoculated on the right ear (Mortatti \& Henriques 1990), while two were inoculated on the right hind footpad in order to make the limiting dilution assay. The group of animals treated on the day of the inoculation (24 animals), was named $P t x-0$, and were sacrificed in the 40th, 80th and 120th days after that date $\left(P t x-O_{40}\right.$, Ptx $-O_{80}$ e $P$ t $x-O_{120}$, respectively). Another group with 16 animals began the same treatment 40 days after the inoculation, and were killed in the 80th and 120th day after that date and were therefore named as $P t x-40_{80}$ e Ptx- $40_{120}$, respectively.

Twenty four animals which did not receive any kind of medicine, became the control group and were killed in the 40th, 80th and 120th after the inoculation date and were named $\mathrm{Ctrl}_{40}, \mathrm{Ctrl}_{80}$ and $\mathrm{Ctrl}_{120}$.
Sacrifice of the animals and limiting dilution assay - The evaluation of lesions of the animals inoculated was conducted through the evolution of the weight difference between the right and left ears (Moratti \& Henriques 1990) of the sacrificed mice, and by the histopathologic analyses, by using a scale from 0 to 6 , according to the inflammatory infiltrate intensity (Magalhães et al. 1986).

The limiting dilution assay was conducted as described by the autors (Titus et al. 1985, Lima et al. 1997), and analyzed by the ELIDA ${ }^{\circledR}$ software (Taswell 1986).

Statistics - In order to evaluate the statistics of two independent samples the data of the histopathologic and the weight difference between the ears, the Mann-Whitney U Test, non-parametric, was used. At the other sampling times, the nonparametric test of Kruskal-Wallis was used for $k$ independent samples and, thereafter, this test was complemented with the multiple comparisons method including all the pairs of treatment. In the study of the weight deviation of the ears the divergent extremes (out-liers) were discarded (Siegel 1977, Campos 1983).

The statistical analysis of the data obtained by the limiting dilution assay was made using ELIDA ${ }^{\odot}$ software (Taswell 1986), which analyses data through the Poisson distribution, and by the minimization statistical method of the chi-square from the data obtained from the plaques, therefore revealing the estimated number of parasites present in the analyzed lesions (Titus et al. 1985).

\section{RESULTS}

Forty days of infection - According to the weight difference between the ears, at the 40th day of infection, a reduction in the average of this difference was obtained in favor of the animals treated with pentoxifylline from the beginning of the infection $\left(P t x-O_{40}\right)$ (Fig. 1), even though this deviation did not have statistical significance $(\mathrm{p}=$ 0.120).

According to the histopathological analyses, some observations had greater prominence than others. In comparison to the control group, there was a reduction of the values corresponding to the whole cellular infiltrated volume - statistically significant $(\mathrm{p}=0.001)$-, to the extent of tissue necrosis $(p=0.294)$ and on the number of vacuolated macrophages $(p=0.242)$, in the lesions of the subgroup of animals that were treated with pentoxifylline. On the other hand, there was an increase on the amount of neutrophils/granulocytes - statistically significant $(\mathrm{p}=0.032)-$, in the subgroup treated with this drug (Figs 2, 3, 4, 5).

The estimation analyses of the number of parasites found on the hind footpad of the animals in- 


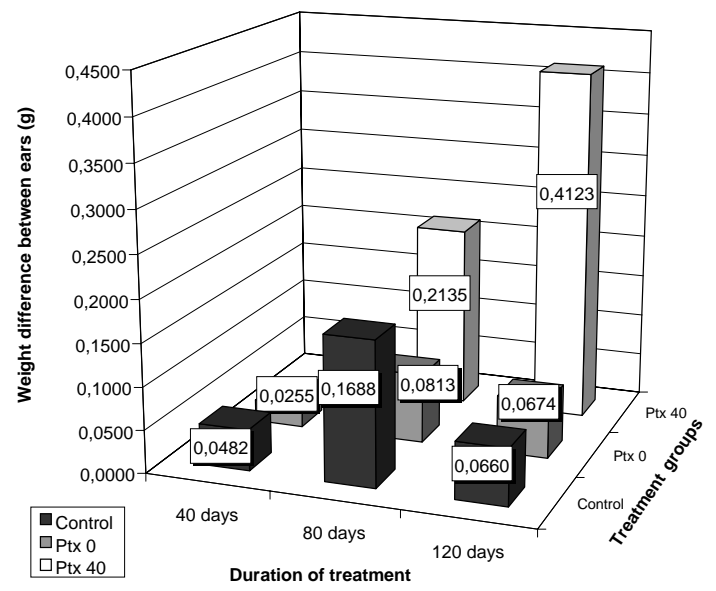

Fig. 1: weight difference between animals' ears

fected on this site, by the limiting dilution assay, showed a significant difference among the treated groups and the control group. In fact, the control group presented an estimated number of parasite forms almost two times higher than the treated group (Fig. 6).

Eighty days of infection - At the 80th day of infection, according to the weight difference between the ears, there was a reduction on the average of this difference among the animals treated with pentoxifylline from the beginning of the infection $\left(\right.$ Ptx $\left.-O_{80}\right)$, in comparison to the control group, and this was statistically significant $(0.01 \leq \mathrm{p} \leq 0.001)$. Moreover, there was an increase of the average of this difference in the subgroup treated from the 40th day of infection $\left(P t x-40_{80}\right)$, in correspondence to the group treated from the beginning of the infection $\left(\right.$ Ptx $\left.-O_{80}\right)$, and this difference was also statistically significant $(\alpha=0.009)$ (Fig. 1).

The histopathological analyses showed changes of the same values previously found for the subgroup treated from the beginning of the infection $\left(\right.$ Pt $\left.x-0_{80}\right)$, but none of them were statistically significant: reduction of the values corresponding to the whole cellular infiltrate, to the areas of necrosis extension $(0.50 \leq \mathrm{p} \leq 0.30)$, and to the number of vacuolated macrophages in the lesions $(0.90 \leq p \leq 0.80)$ and to the increase in the amount of neutrophils/granulocytes $(0.10 \leq \mathrm{p} \leq 0.05)$ in the subgroup treated with this drug. The analyses of the subgroup treated from the 40th day (Ptx$40_{80}$ ) in correspondence to the control group did not show statistical significance, there was an increase in the volume of the whole cellular infiltrate, of the necrosis area extension, and of the amount of neutrophils granulocytes in the tissue, but there was a reduction in the amount of vacuolated macrophages in the lesions (Figs 2, 3, 4, 5).

The estimated number of parasites found on the hind footpad of the animals infected with the limiting dilution assay showed a significant difference among the treated groups and the control group, with the treated group presenting an esti-

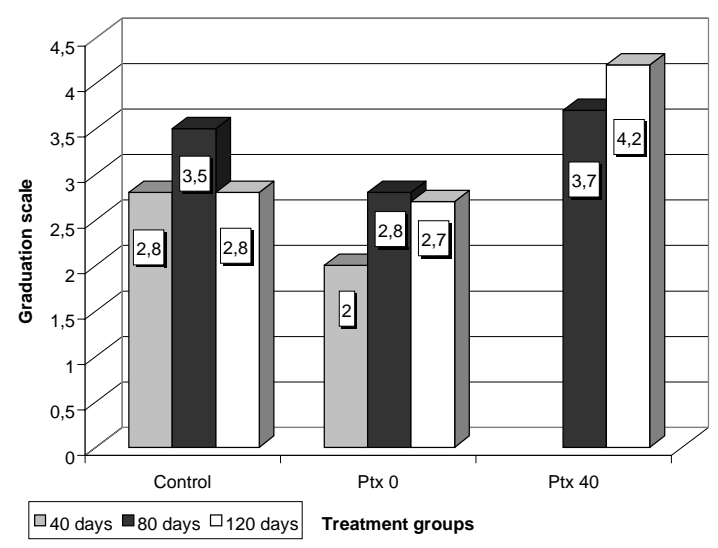

Fig. 2: evaluation of the whole cellular infiltrate

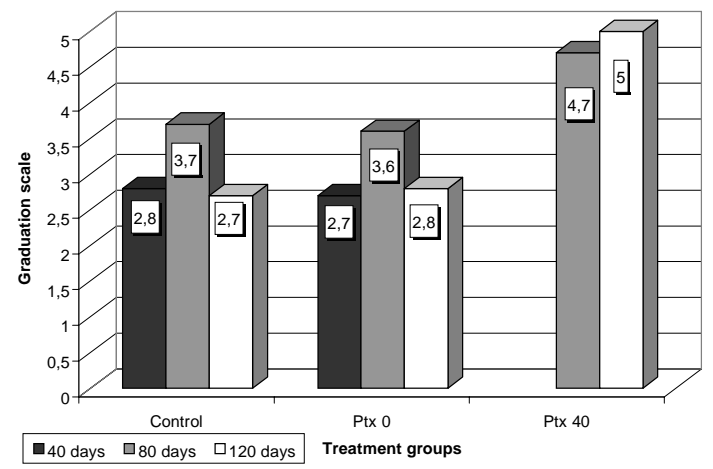

Fig. 3: evaluation of the necrosis area extension

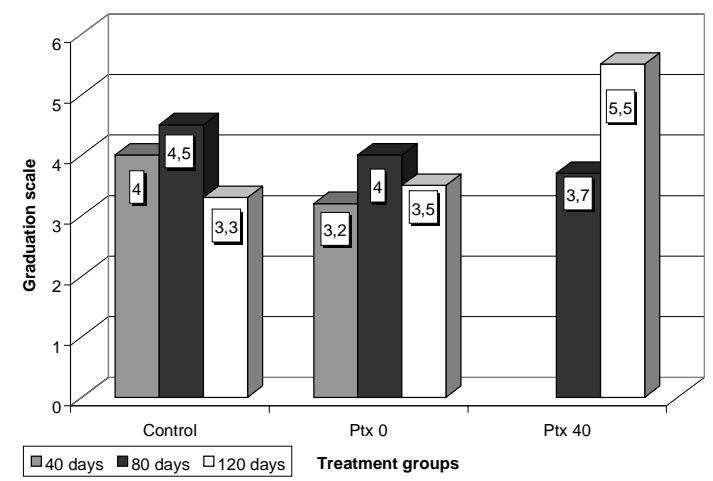

Fig. 4: evaluation of the number of vacuolated macrophages 


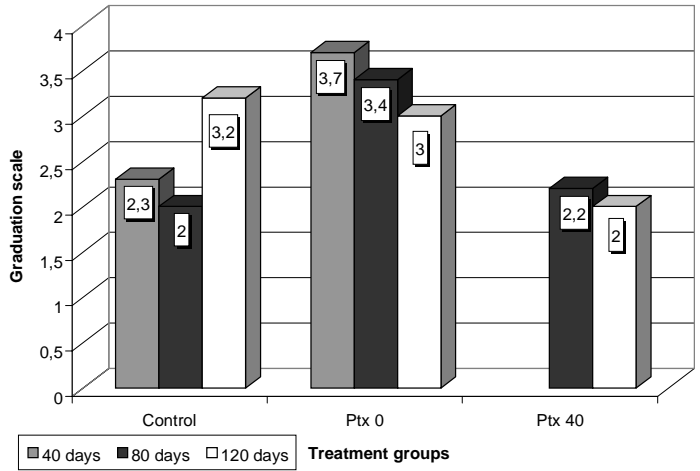

Fig. 5: evaluation of the number of neutrophils granulocytes

mated number of forms almost 43 times higher than the group treated from the beginning of the infection $\left(P t x-O_{80}\right)$. In addition, the subgroup treated from the 40th day $\left(\right.$ Ptx $\left.-40_{80}\right)$ also demonstrated a great increase, approximately three times more than the estimated number of forms detected in the control group (Fig. 6).

One hundred and twenty days of infection - At the 120th day of infection the average of the weight difference between the ears was equivalent between treated $\left(\right.$ Ptx- $\left.O_{120}\right)$ and control group. In the subgroup treated from the 40th day of infection $\left(P t x-40_{120}\right)$ there was, on the other hand, a statistically significant increase $(\mathrm{p} \leq 0.001)$ of the averages of the differences in comparison to the control group $(\alpha=0.011)$ and to the subgroup treated from the beginning of the infection $\left(P t x-O_{120}\right)(\alpha=0.049)$ (Fig. 1).

Regarding the histopathological analyses, the subgroup treated from the 40th day $\left(\right.$ Ptx $\left.-40_{120}\right)$ showed a meaningful, statistically significant, in-

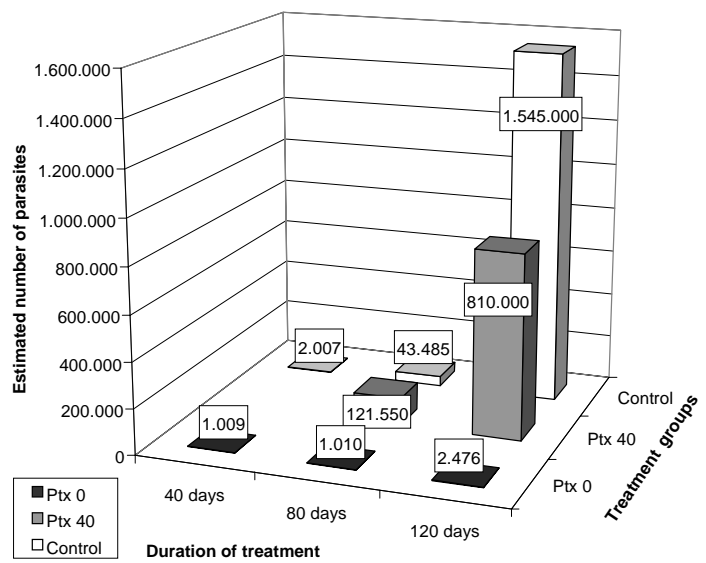

Fig. 6: parasite burdens as assessed by limiting dilution assay crease in the volume of the whole cellular infiltrate $(0.05 \leq \mathrm{p} \leq 0.02)$ in comparison to the control group $(\alpha=0.045)$, of the intensity of the tissue necrosis $(0.02 \leq \mathrm{p} \leq 0.01)$, either in comparison to the control group $(\alpha=0.049)$ or in comparison to the subgroup treated from the beginning of the infection (Ptx$\left.O_{120}\right)(\alpha=0.049)$. In this subgroup, the level of neutrophils/granulocytes was below that observed in the control group $(0.3 \leq \mathrm{p} \leq 0.2)$ (Figs 2, 3, 4, 5).

Using the limiting dilution assay, the estimated number of parasites showed a significant reduction for the treated subgroup in comparison to the control group, which presented an estimated number of parasite forms almost 624 times greater than the group treated from the beginning of the infection $\left(P t x-O_{120}\right)$. In the subgroup treated from the 40th day of infection $\left(P t x-40_{120}\right)$, the estimated number of parasite forms was reduced by $50 \%$, in comparison to the control group (Fig. 6).

\section{DISCUSSION}

The subgroup, that received treatment from the beginning of the infection by Leishmania (Ptx-O) presented a significantly lower parasite load than the control group $(\mathrm{Ctrl})$ during the whole experimental period. There was a decrease in the inflammatory process in the animals treated in the Ptx- 0 subgroup, in comparison to the control subgroup $(C t r l)$, which produced both a reduction in the average weight deviation of the ears, a decrease in the whole cellular infiltrate, and of the number of vacuolated macrophages. The reduction in the quantity of vacuolated macrophages as well as the high number of neutrophils/granulocytes in the Ptx-O subgroup suggests the existence of an important role for these cells in the experimental infection.

The anti-parasitic action of TNF- $\alpha$ resides on a well known activity, but the authors usually emphasize that this cytokine seems to have an efficient role in the modulation of the proinflammatory response only if the levels are adequate, in other words, when there is no exacerbation of its action. High levels of TNF- $\alpha$ leave the beneficial action over the defense cells with autocrine and paracrine actions, to exert more general actions, of endocrine character, not favoring the inflammatory process (Vissers et al. 1989, Jaattela 1991, Abbas et al. 1995, Da-Cruz et al. 1996). The observations with the Ptx-O subgroup seem to result from a pronounced action of the defense cells stimulated by the levels of TNF- $\alpha$ modulated by pentoxifylline. This optimal level, might have allowed a better local action of TNF- $\alpha$ with improved results upon the above mentioned cells, and, therefore, over the infection. The control of these levels by the drug seems to exercise some power over the macrophages, transforming them 
into cells with enhanced phagocytic activity which would then contribute to the reduction of their own parasitism (Moll et al. 1990, Abbas et al. 1995). The role of pentoxifylline in the initial phase of the infection by Leishmania remains unclear, but there was an explicit improvement in the lesion during this phase of the experimental model. More studies measuring these molecules levels at the sites of infection would be helpful to elucidate our hypothesis.

The inflammatory response to the presence of Leishmania in the tissues is not usually specific in the initial phases of infection (Th-0), and remains this way for approximately 60 days after the infection (Titus et al. 1989, Scharton \& Scott 1993). There was an increase on the quantity of parasites in the Ptx-40 subgroup, 80 days after the infection. During this period, the inflammatory response, which seemed to be non-specific, turned out to be stimulated by pentoxifylline. One possibility would be an initial deviation towards a Th-2 response, through the inhibition of the pro-inflammatory cytokines, such as IL-12, which are essential during this phase of the infection (Scharton-Kersten et al. 1995, Solbach W \& Laskay 1996, Moller et al. 1997). Confirmatory studies measuring these possible involved molecules, such as IL-12 in this phase of inflammation, are necessary to corroborate our preliminary thoughts

At later stages of the study, after 120 days of infection, it was noticed that the Ptx-40 subgroup began to present a lower number of parasites than the control group. There are reports suggesting that the level of IFN- $\gamma$, and of TNF- $\alpha$, show a great increase during the process of infection, reaching their maximum values in the latest phases (Titus et al. 1989, Kunkel et al. 1989, Scharton \& Scott 1993, Melby et al. 1994, Reiner et al. 1994). At the present moment, the pentoxifylline used must have exerted a modulating activity upon the high level of these cytokines, making the inflammatory response adequate to a more effective action, which resulted in a lower degree of parasitism in the $P t x-40_{120}$ subgroup than in the control group. Once again there is necessary confirmatory studies to elucidate these data.

The analyses of the averages of the weight deviation of the ears revealed a similar pattern to the data recorded for the quantity of parasites, hence the inflammation in the Ptx-40 subgroup was enhanced during the course of the experiment. The histopathological analyses revealed an increase in both the whole cellular infiltrate and the number of vacuolated macrophages, after 120 days of infection, in comparison to control group, demonstrating a progressive increase in the inflammatory response, which was to be expected due to the pos- sible reestablishment of a Th-1 pattern. The necrosis in the $P t x-40$ subgroup was enhanced due the high levels of parasitism, maybe due the possible initial deviation toward Th- 2 in this subgroup, what surpassed the inhibitory action of pentoxifylline over elastasis.

During the course of the study, it was observed that pentoxifylline seems to possess particular actions and effects when used in a precocious phase or when used at the first visible signs of the disease. The response pattern is different in both situations, so that it reinforces the idea that the host response to the parasite constitutes a complex game between pro and anti-inflammatory cytokines, the results of which may define the prognosis of the disease.

\section{ACKNOWLEDGEMENTS}

To Prof. José Hermênio Cavalcante Lima Filho, from the Federal University of Santa Catarina, for his valuable collaboration and help with the limiting dilution assay. To Prof. Eilson Goes de Oliveira, from the Federal University of Ceará, who provided valuable and critical statistical discussion.

\section{REFERENCES}

Abbas AK, Lichtman HA, Pober SJ 1995. Citocinas. In Imunologia Celular e Molecular, Revinter, Rio de Janeiro, p. 239-257.

Barral-Netto M, Barral A 1994. Transforming growth factor- $\beta$ in tegumentary leishmaniasis. Braz J Med Biol Res 27: 1-9.

Borish L, Rosenwasser JL 1996. Update on cytokines. J Allergy Clin Immunol 97: 719-734.

Campos H 1983. Estatística Experimental Não Paramétrica, 4th ed., Escola Superior de Agricultura Luiz de Queiroz, Piracicaba, 349 pp.

Cerami A 1992. Inflammatory cytokines. Clin Immunol Immunopathol 62: S3-S10.

Da-Cruz MA, Oliveira PM, De Luca MP, Mendonça FCS, Coutinho GS 1996. Tumour necrosis factor- $\alpha$ in human American tegumentar leishmaniasis. Mem Inst Oswaldo Cruz, 91: 225-229.

Doherty GM, Jensen JC, Alexander HR, Buresh CM, Norton JA 1991. Pentoxifylline suppression of tumor necrosis factor gene transcription. Surgery 110 : 192-198.

Hand LW, Butera LM, King-Thompson LN, Hand LD 1989. Pentoxifylline modullation of plasma membrane functions in human polymorphonuclear leukocytes. Infect Immun 57: 3520-3526.

Jaattela M 1991. Biologic activities and mechanics of action of tumour necrosis factor- $\alpha /$ cachetin. $L a b$ Invest 64: 724-735.

Kunkel SL, Chensue SW, Strieter RM, Lynch JP, Remick DG 1989. Cellular and molecular aspects of granulomatous inflammation. Am J Resp Cell Mol Biol 1: 439-447.

Liew FY, Li Y, Millott S 1990a. Tumour necrosis factor- $\alpha$ synergizes with IFN- $\gamma$ in mediating killing of Leishmania major through the induction of nitric 
oxide. J Immunol 145: 4306-4310.

Liew FY, Parkinson C, Millott S, Seuern A, Carrier M 1990b. Tumour necrosis factor (TNF-alpha) in leishmaniasis. 1. TNF-alpha mediates host protection against cutaneous leishmaniasis. Immunology 69: 570573.

Lima HC, Bleyenberg JA, Titus RG 1997. A simple method for quantifying Leishmania in tissues of infected animals. Parasitol Today 13: 80-82.

Loftis LL, Meals AE, English KB 1997. Differential efects of pentoxifylline and interleukin-10 on production of tumour necrosis factor and inducible nitric oxide synthase by murine macrophages. J Infect Dis 175 : 1008-1011.

Magalhães AV, Moraes MAP, Raick AN, Llanos-Cuentas A, Costa JML, Cuba CC, Marsden PD 1986. Histopatologia da leishmaniose tegumentar por Leishmania braziliensis braziliensis. 1. Padrões histopatológicos e estudo evolutivo das lesões. Rev Inst Med Trop São Paulo 28: 253-262.

Melby CP, Andrade-Narvaes JF, Darnell JB, ValenciaPacheco G, Tryon VV, Palomo-Cetina A 1994. Increased expression of proinflammatory cytokines in chronic lesions of human cutaneous leishmaniasis. Infect Immun 62: 837-842.

Moll H, Binöder K, Bogdan C, Solbach E, Röllinghoff H 1990. Production of tumour necrosis factor during murine cutaneous leishmaniasis. Parasite Immunol 12: 483-494.

Moller RD, Wisocka M, Greenlee MB, Ma X, Wahl L, Trinchieri G, Karp LC 1997. Inhibition of human interleukin-12 production by pentoxifylline. Immunology 91: 197-203.

Mortatti RC, Henriques A 1990. Experimental cutaneous leishmaniasis by Leishmania amazonensis: Course of fast growth infection in the mouse ear. Parasitol Res 76: 729-730.

Mukherjee A, Seth M, Bhaduri PA 1990. Present status of leishmaniasis. Progr Drug Res 34: 448-479.

Neuner P, Klosner G, Schauer E, Pourmojib M, Macheiner W, Grunwald C, Knobler R, Schwarz A, Luger AT, Schwarz T 1994. Pentoxifylline in vivo downregulates the release of IL-1 $\beta$, IL-6, IL-8 and tumour necrosis factor- $\alpha$ by human peripheral blood mononuclear cells. Immunology 83: 262-267.

Reed RW, Degowin LR 1992. Supressive effects of pentoxifylline on natural killer cell activity. $J \mathrm{Lab}$ Clin Med 119: 763-770.

Reiner LS, Zheng S, Wang ZE, Stowring L, Locksley MR 1994. Leishmania promastigotes evade interleukin 12 (IL-12) induction by macrophages stimulated a broad range of cytokines from CD4+ T cells during initiation of infection. J Exp Med 179: 447-456.

Schade UF 1990. Pentoxifylline increases survival in murine endotoxin shock and decreases formation of tumor necrosis factor. Circul Shock 31: 171-181.

Schandené L, Vandenbussche P, Crusiaux A, Alègre ML, Abramowicz D, Dupont E, Content J, Goldman M 1992. Differential effects of pentoxifylline on the production of tumour necrosis factor-alpha (TNFalpha) and interleukin-6 (IL-6) by monocytes and T cells. Immunology 76: 30-34.
Scharton MT, Scott P 1993. Natural killer cells are a source of interferon- $\gamma$ that drives differentiation of CD4+ T cells subsets and induces early resistance to Leishmania major in mice. J Exp Med 178: 567-577.

Scharton-Kersten T, Afonso CCL, Wysocka M, Trinchieri G, Scott P 1995. IL-12 is required for natural killer cell activation and subsequent $\mathrm{T}$ helper 1 cell development in experimental leishmaniasis. $J$ Immunol 154: 5320-5346.

Siegel S 1977. Estatística Não-paramétrica. Para as Ciências do Comportamento, McGraw-Hill, São Paulo, 350 pp.

Solbach W, Laskay T 1996. Evasion strategies of leishmania parasites. In FJ Tapia, G Caceres Dittmar, MA Sanchez (eds.), Molecular and Immune Mechanism in the Pathogenesis of Cutaneous Leishmaniasis, (Series: Medical Intelligence Unit), RG Landes, Georgetown, p. 25-47.

Strieter RM, Remick DG, Ward PA, Spengler RN, Lynch III JP, Larrick J, Kunkel SL 1988. Cellular and molecular regulation of tumor necrosis factor-alpha production by pentoxifylline. Biochem Biophys Res Commun 155: 1230-1236.

Sullivan GW, Carper HT, Novick Jr WJ, Mandell GL 1988. Inhibition of the inflammatory action of interleukin-1 and tumor necrosis factor (alpha) on neutrophil function by pentoxifylline. Infect Immun 56: $1722-1729$.

Taswell C 1986. Limiting dilution assays for the separation, characterization and quantification of biologically active particles and their clonal progeny. In TC Pretlow \& TP Pretlow (eds), Cell Separation: Methods and Selected Applications, Academic Press, New York, p. 109-145.

Titus GR, Sherry B, Cerami A 1989. Tumour necrosis factor plays a protective role in experimental murine cutaneous leishmaniasis. J Exp Med 170: 2097-2104.

Titus RG, Marchand M, Boon T, Louis JA 1985. A limiting dilution assay for quantifying Leishmania major in tissues of infected mice. Parasite Immunol 7: 545-556.

Van Furth MA, Verhard-Seijmonsbergen ME, Van Furth R, Langermans MAJ 1997. Effect of lisofylline and pentoxifylline on the bacterial-stimulated production of TNF- $\alpha$, IL-1 $\beta$ and IL-10 by human leukocytes. Immunology 91: 193-196.

Varani J, Bendelow MJ, Sealey DE, Kunkel SL, Gannon DE, Ryan US, Ward PA 1988. Tumor necrosis factor enhances susceptibility of vascular endothelial cells to neutrophil-mediated killing. Lab Invest 59: 292-295.

Vissers MCM, Fantone JC, Wiggins R, Kunkel SL 1989. Glomerular basement membrane-containing immune complexes stimulate tumor necrosis factor and interleukin-1 production by human monocytes. Am J Pathol 134: 1-6.

Weinberg JB, Mason SN, Wortham TS 1992. Inhibition of tumor necrosis factor-alpha (TNF-alpha) and interleukin 1-beta (IL 1-beta) messenger RNA (mRNA) expression in HL-60 leukemia cells by pentoxifylline and dexamethasone: dissociation of acivicin-induced TNF-alpha and IL 1-beta mRNA expression from acivicin-induced monocytoid differentiation. Blood 79: 3337-3343. 